\title{
Exercitar as Funçôes Psíquicas: Ortopedia Mental como Método de Ensino das Classes Especiais (1930) ${ }^{1}$
}

\author{
EXERCISING PSYCHIC FunCTIONS: MENTAL ORTHOPEDICS AS a TEACHING \\ METHOD FOR STUDENTS WITH ESPECIAL NEEDS (1930)
}

\author{
Laênia Martins PETERSEN ${ }^{2}$ \\ Raquel Martins ASSIS ${ }^{3}$
}

\begin{abstract}
RESUMO: a pesquisa apresentada investigou o método de Ortopedia Mental elaborado pela educadora Helena Antipoff, enfocando seus fundamentos teóricos. Utilizamos como fontes os textos da educadora escritos na década de 1930 e compilados em dois volumes da Coletânea das obras escritas de Helena Antipoff: Psicologia Experimental e Educaçáo do excepcional. Helena Antipoff dirigiu o Laboratório de Psicologia da Escola de Aperfeiçoamento de Belo Horizonte, instituição de formação de professores e técnicos em Educação. Processos de homogeneizaçáo de classes faziam parte da reforma proposta a partir de 1927. Durante a implantação das classes homogêneas, entre 1930 e 1935, a psicóloga russa fez uma crítica à limitação dessa ação isolada e concluiu que apenas a homogeneização não traria resultados suficientes para a aprendizagem e o desenvolvimento dos alunos. Antipoff empenhou-se em propor programas que pudessem oferecer à criança um ensino que respeitasse suas particularidades, ao mesmo tempo que treinasse professores para sua execução. Um desses programas era a Ortopedia Mental, técnica utilizada por Binet, e para a qual a educadora adaptou princípios educacionais e procedimentos de vários autores. Na aplicação da Ortopedia Mental, Helena Antipoff valorizava o empenho, a criatividade e o envolvimento que o professor deveria ter com sua classe na elaboração de atividades capazes de despertar o interesse das crianças e desenvolver, ao mesmo tempo, suas faculdades mentais.
\end{abstract}

PALAVRAS-CHAVE: Educaçâo Especial. Estimulação Cognitiva. Helena Antipoff.

\begin{abstract}
The present research investigated the Mental Orthopedics method developed by the educator Helena Antipoff, focusing on its theoretical foundations. As sources, we have used the educator's texts written in the 1930's and compiled into two volumes of The Collection of Helena Antipoff's writings: Experimental Psychology and Education of Exceptional Students. Helena Antipoff directed the Psychology Laboratory of Belo Horizonte Improvement School, an institution designed for training teachers and technicians in education. Class homogenization was part of the proposed reform from 1927 on. During the implementation of homogeneous classes, between 1930 and 1935, the Russian psychologist criticized the limitations of this isolated action and concluded that homogenization alone would not bring sufficient results to the students' learning and development. Antipoff endeavored to propose programs that could offer the child an education that respected the students' particularities and offered the teachers the required training to carry out the program. One of these programs was the Mental Orthopedics, a technique used by Binet, and to which the educator adapted educational principles and procedures from several authors. In the application of the Mental Orthopedics, Helena Antipoff valued the commitment, the creativity and the involvement the teacher should have before their students when developing activities that stimulated children's interest and, at the same time, developed their mental skills.
\end{abstract}

KEYWORDS: Special Education. Cognitive Stimulation. Helena Antipoff.

\section{INTRODUÇÃo}

O conceito de Ortopedia Mental foi utilizado pelo psicólogo francês Alfred Binet (1857-1911), no início do século XX, para se referir a um conjunto de exercícios psicomotores destinados a promover o desenvolvimento das capacidades intelectuais das crianças. Tratava-

\footnotetext{
${ }^{1}$ http://dx.doi.org/10.1590/S1413-65382317000100010

${ }^{2}$ Docente do Departamento de Psicologia da Pontifícia Universidade Católica de Minas Gerais. Belo Horizonte, MG, Brasil. laeniamartins@gmail.com

${ }^{3}$ Docente da Faculdade de Educação da Universidade Federal de Minas Gerais e do Programa de Pós-Graduação em Educação. Belo Horizonte, MG, Brasil. rmassis.ufmg@gmail.com
} 
se de um treinamento constituído de exercícios sistemáticos e repetitivos a fim de fortalecer e organizar as faculdades mentais, apurar os sentidos e melhorar a percepção de modo a propiciar o desenvolvimento infantil.

No Brasil, na década de 1930, Helena Antipoff, inspirada em Alfred Binet, propôs a Ortopedia Mental como método a ser utilizado nas classes especiais de Minas Gerais que começavam a ser organizadas a partir do processo de homogeneização das classes proposto pela Reforma de Ensino de 1927. Nesse processo, os escolares eram avaliados por meio dos testes de inteligência muito em voga na época (ROTA JÚNIOR, 2016). As salas especiais foram criadas nas escolas mineiras para atender as crianças cujo desempenho havia sido insatisfatório nos testes aplicados. Face à necessidade de criar instrumentos pedagógicos para esse grupo de alunos, Antipoff começou a se interessar pela educação das crianças consideradas anormais e pela elaboração de métodos que pudessem propiciar o desenvolvimento dessas turmas (BORGES, 2014). Entre os recursos pedagógicos utilizados para tais fins, a Ortopedia Mental foi empregada por Antipoff em seu trabalho com aqueles que mais tarde ela nomearia 'excepcionais', quando foi responsável pelo Laboratório de Psicologia da Escola de Aperfeiçoamento de Belo Horizonte/Minas Gerais. A partir de suas propostas em psicologia e de suas iniciativas educacionais, a educadora russa tornou-se uma referência importante para a educação especial de sua época, sendo citada como pioneira desse campo no texto da Política Nacional de Educação Especial aprovado em 2008.

Helena Antipoff veio para Belo Horizonte/MG, em 1929, a convite do governo mineiro para contribuir com a reforma educacional planejada, em 1927, por Francisco Campos e Mário Casassanta. Uma de suas funçóes era dirigir o Laboratório da Escola de Aperfeiçoamento, que fora implantado em 1928 por Théodore Simon (1872-1961), com a finalidade de fazer pesquisas e formar professores e técnicos para atender a grande demanda de alunos oriunda das escolas e para promover a reforma que visava a uma renovação educacional capaz de superar os métodos considerados tradicionais (CAMPOS, 2012).

Alicerçadas nos movimentos escolanovistas, as reformas educacionais brasileiras, ocorridas nos anos de 1920, tinham como objetivo introduzir métodos de ensino que suplantassem a educação clássica a fim de promover uma transformação nos processos de ensino e de aprendizagem. A Escola Nova propunha reformar a escola em torno de uma pedagogia científica voltada para as necessidades da criança, levando em conta as diferenças individuais, as características físicas e psicológicas da infância e o interesse dos alunos (LOURENÇO FILHO, 2002; GUTIERREZ; BESSE; PROST, 2014; BORGES, 2014).

No âmbito da reforma educacional, uma das funções de Helena Antipoff e de sua equipe de professoras-alunas era empreender a homogeneização das classes, trabalho similar àquele feito por Alfred Binet na Reforma do Ensino na França em 1904. Para instrumentalizar essa ação, Alfred Binet e Théodore Simon criaram a Escala Métrica de Inteligência, que levou seus nomes. A Escala Binet-Simon foi utilizada como um dos instrumentos para separar as crianças em turmas conforme seu nível mental (NICOLAS et al., 2013; ROTA JÚNIOR, 2016). Atualmente, a divisão em classes homogêneas pode ser entendida como um processo que criou segregação, mas é importante considerar que, na época, se esperava que as salas homogêneas pudessem proporcionar um parâmetro para que os professores desenvolvessem métodos de instrução adequados às particularidades e possibilidades de aprendizagem das crianças 
de cada turma. Pretendia-se, portanto, propiciar melhores condiçóes educacionais para alunos que se encontravam em situaçóes diversas quanto à aprendizagem.

Quando estava em Paris (1909-1912), querendo expandir e colocar em prática seus conhecimentos em psicologia, Antipoff fez seu estágio com Théodore Simon, parceiro de Binet na avaliação de crianças com a Escala Métrica de Inteligência. Assim, ela participou da testagem da Escala Binet-Simon (CAMPOS, 2012; BORGES, 2014). Nesse laboratório, conheceu o psicólogo Édouard Claparède, estudioso da Psicologia ativa e incentivador do escolanovismo. Mais tarde, Antipoff se tornaria assistente de Claparède, passando a integrar sua equipe no Instituto Jean-Jacques Rousseau (IJJR), em Genebra (CAMPOS, 2012).

Em 1917, devido a grave ferimento sofrido por seu pai na guerra, Antipoff regressou à Rússia, onde trabalhou na reeducação de crianças órfấs de guerra. Também colaborou com a pesquisa de Aleksandr Petrovich Nechaevna (1870-1948) investigando a influência da guerra no desenvolvimento mental de crianças em idade pré-escolar. No entanto, ao apresentar resultados de estudos segundo os quais o nível mental dos filhos de intelectuais era mais alto comparado ao das outras crianças, Antipoff foi criticada por intelectuais ligados ao recém-implantado regime soviético e acabou tendo que deixar o país. Em 1925, reatou sua ligação com o Instituto Jean-Jacques Rousseau, onde se estabeleceu até receber o convite para trabalhar no Brasil (CAMPOS, 2012).

Como é possível observar, Antipoff teve uma experiência ampla e diversificada na educação por atuar em várias instituições que trabalhavam com escolares ou que atendiam crianças órfấs e/ou consideradas "anormais". Sua proposta de Ortopedia Mental para as classes especiais mineiras deve ser entendida levando em consideração sua experiência em investigaçóes psicológicas e também seu diálogo com a realidade local encontrada nas escolas de Minas Gerais. Para Borges (2014, p. 348), as “classes especiais implantadas em Belo Horizonte constituíram-se como um importante exemplo da circulaçáo do conhecimento e de como uma cultura absorve e transforma conceitos". Este artigo, ao descrever a proposta de Ortopedia Mental feita por Antipoff, pretende evidenciar como os recursos pedagógicos criados para as classes especiais expressaram a apropriação de conceitos e práticas desenvolvidas na França e Suíça, e reelaborados à luz dos problemas brasileiros.

\section{MÉTOdo DA PESQUISA}

Utilizamos aportes da História da Psicologia com ênfase na historiografia das ciências. Segundo Massimi (2012), o pesquisador deve se preocupar em interpretar concepçóes e soluçóes do passado sem presentismo, atendo-se aos acontecimentos da época. Para investigar a proposta de Ortopedia Mental elaborada por Helena Antipoff, sustentamos nossa análise em textos da educadora escritos na década de 1930 e compilados em dois volumes da Coletânea das obras escritas de Helena Antipoff: Psicologia Experimental (v. I, 1992a) e Educação do excepcional (v. III, 1992b); no Boletim 14, intitulado Ortopedia Mental nas classes especiais, escrito por Helena Antipoff e Naitres de Rezende (1934); e no ensaio "Outros testes e aplicações", Théodore Simon (1930). Foi necessário ainda buscar no arquivo mineiro e na imprensa oficial

\footnotetext{
${ }^{4}$ Naitres de Rezende era auxiliar do Laboratório de Psicologia e participava ativamente, ao lado de Antipoff, nas atividades de organização e assistência às classes especiais (BORGES, 2014).
} 
a obtenção de documentos que contextualizassem o momento político do estado de Minas Gerais, como o conteúdo do Regulamento do Ensino primário e da Escola Normal que continha o posicionamento do responsável de implantar a reforma do ensino: o secretário do Interior, Francisco Campos. Livros de Alfred Binet, Alice Descoeudres e Maria Montessori também foram consultados.

A leitura e análise dos textos forneceram três categorias a partir das quais foi possível compreender a proposta elaborada por Antipoff: definição de ortopedia mental e orientação aos professores; fundamentação teórica da ortopedia mental e influência dos autores Alfred Binet, Maria Montessori e Alice Descoeudres; os exercícios de ortopedia mental.

Nessa perspectiva, este artigo apresentará a proposta de Ortopedia Mental elaborada por Helena Antipoff na década de 1930, levando em consideração as preocupaçóes da época e do contexto mineiro acerca da educação das crianças anormais. Apresentaremos a organização das classes especiais nas escolas de Minas Gerais, contexto em que seu deu a utilização da ortopedia mental. Em seguida, descreveremos o método de ortopedia mental proposto por Helena Antipoff, trazendo elementos das categorias elencadas acima.

\section{As CLASSES ESPECIAIS}

Para atender a intenção de popularizar o ensino, no contexto da reforma educacional, Helena Antipoffe as professoras-alunas da Escola de Aperfeiçoamento ficaram responsáveis por separar as crianças em grupos homogêneos que pudessem formar turmas de acordo com a relação estabelecida entre coeficiente mental e idade real (BORGES, 2014). A fim de levar adiante essa tarefa, a educadora russa e sua equipe iniciaram, em 1931, a aplicação de três instrumentos diferenciados para medir a inteligência:

O teste do desenho da figura humana, inventado pela psicóloga norte-americana Florence Goodenough; o teste de jogos e quebra-cabeças elaborado por Walter Dearborn, psicólogo educacional formado pela Universidade de Columbia, em Nova York; e finalmente o teste das 100 questôes de Ballard (CAMPOS, 2012, p. 233).

A análise dos resultados dos testes aplicados pela pesquisadora em Belo Horizonte, na separação das classes por nível mental, demonstrou que algumas crianças apresentavam quocientes intelectuais inferiores à média normatizada. Para atender a esse público foram criadas as já citadas classes especiais, previstas desde 1927 pelo regulamento da instrução pública de Minas Gerais (ANTIPOFF, 1992b).

Os resultados dos testes das crianças de Belo Horizonte, acrescidos das experiências que tivera com crianças abandonadas na Rússia no período de 1920 a 1924, em virtude da Primeira Grande Guerra, fizeram com que Helena Antipoff começasse a questionar a ideia predominante na época de que os testes eram capazes de medir a inteligência natural. A pesquisadora desenvolveu consideraçóes sobre o constructo da inteligência, tecendo certa crítica à maneira como Binet o definia nos testes. Antipoff acreditava que a forma como a inteligência se revelava diante das atividades propostas pelos testes não poderia ser compreendida sem levar em consideração a experiência da criança no contexto em que estava inserida. A partir dessa concepção e na contramão do pensamento inatista, ela elaborou o conceito de "inteligência 
civilizada”, segundo o qual a inteligência sofre a intervenção do ambiente social (CAMPOS, 2012). Observou em suas investigaçóes que, mesmo crianças que não apresentavam nenhum retardo aparente, isto é, crianças mais pobres ou em situação de abandono, expostas a menos estímulos educacionais, apresentavam nos testes resultados abaixo da média normatizada.

O conceito de inteligência civilizada implicava a ação do ambiente sobre as faculdades mentais e, consequentemente, valorizava a educação como aspecto fundamental do desenvolvimento das crianças, mesmo daquelas consideradas anormais (BORGES, 2014). Dessa forma, era necessário que o trabalho desenvolvido nas classes especiais pudesse dispor de métodos e recursos capazes de beneficiar os pequenos aprendizes.

No processo de homogeneização das classes dos grupos escolares, foram criadas as classes especiais $\mathrm{C}$ e $\mathrm{D}$ para atender os alunos que apresentassem um desempenho inferior nos testes de inteligência: "A classe $C$ receberá crianças com atraso de desenvolvimento até três anos, crianças de espírito adormecido, ou turbulentas, mas sem defeitos notáveis no físico como no moral." (ANTIPOFF, 1992b, p. 157). A classe D, denominada "classe de educação individual", foi criada para receber crianças com atraso mental severo, comprometimentos físicos e/ou psíquicos e que precisavam de condiçóes especiais para seu desenvolvimento.

Em 1933, após uma viagem à Bélgica, França e Suíça com finalidade de visitar os estabelecimentos que trabalhavam com crianças anormais, Helena Antipoff fez uma palestra ao Conselho Técnico da Sociedade Pestalozzi, em que, ao relatar o que havia visto em outros países, propunha uma nova distribuição de classes para a educação especial, acrescentando a classe E: "As classes E, estão em vigor na rede escolar da cidade de Zurich e outras, onde essas Erziehungsklassen [aulas de educação] produziram o melhor resultado" (ANTIPOFF, 1992a, p. 41). As classes E seriam compostas por crianças difíceis de educar:

Um grupo receberá as crianças indisciplinadas, ou associais puros, os rixentos de alma grosseira e brutal que, muitas vezes, sem constituição patológica e tarada, não fazem senão revelar a miséria social de seu meio (ANTIPOFF, 1992b, p. 48).

As classes especiais então passaram a ser $\mathrm{D}$ e $\mathrm{E}$ (e não mais $\mathrm{C}$ e $\mathrm{D}$ ). A classe $\mathrm{D}$ era formada exclusivamente por crianças de inteligência débil, segundo classificação da época, e poderia ser subdividida em até três grupos para atender a diversas deficiências. A classe E, como já visto, foi criada para atender crianças de inteligência normal, mas que, por serem turbulentas, não conseguiam seguir a turma regular.

As divisóes das classes eram concebidas para atender as variadas necessidades dos escolares, visando ao seu maior desenvolvimento. A dinâmica das turmas deveria ser móvel, ou seja, o estudante teria a oportunidade de passar de uma classe para outra, conforme seu desenvolvimento, já que era feito um registro periódico pelos professores, proporcionando às crianças a oportunidade de obter promoçóes individuais (ANTIPOFF, 1992a).

Do ponto de vista prático, considerava-se que a criação de classes homogêneas favorecia tanto os alunos, quanto os professores. Antipoff afirmava que nas classes heterogêneas, com um grande número de alunos, o professor tendia a fixar sua atenção na maioria que acompanhava aquilo que estava sendo transmitido, deixando de dar apoio aos mais lentos. Como 
consequência, esse aluno poderia ser reprovado, sem que sua dificuldade fosse sanada. Já nas salas homogêneas, os escolares se beneficiariam de conteúdos que atendiam diretamente a sua dificuldade (ANTIPOFF, 1992b). Os professores, por sua vez, ganhariam a oportunidade de desenvolver habilidades, trabalhando sua rigidez em dar tarefas padronizadas e impessoais que muitas vezes se limitavam a "instruir" sem levar em consideração os interesses e necessidades dos alunos. Aos docentes, era preconizado que eles procurassem saber os pontos fracos e fortes de seus alunos das classes especiais, fazendo um estudo minucioso do material sobre a criança produzido pela medicina e pela psicologia.

Dessa maneira, os docentes poderiam intervir diretamente sobre a necessidade do estudante. Sob esse ponto de vista, cada sala de aula era vista como um laboratório de variadas possibilidades de experimentação. A equipe de professoras-alunas sob a responsabilidade de Antipoff realizava um trabalho de auxílio e de orientação aos professores das classes $\mathrm{D}$, ensinando Ortopedia Mental e indicando exercícios a serem trabalhados com as crianças. No Laboratório de Psicologia da Escola de Aperfeiçoamento aconteciam reunióes às quintas-feiras pela manhã, nas quais as professoras das classes especiais poderiam buscar subsídios para o seu trabalho (BORGES, 2014).

A educadora russa acreditava que o melhor método pedagógico para atender crianças excepcionais era produzido na interação com elas. Nessa perspectiva, pautou-se pelo trabalho de Alice Descoeudres, psicóloga e educadora do Instituto Jean-Jacques Rousseau, observando seus princípios para o ensino especial, e o estendeu aos alunos considerados "normais". Dentre esses pressupostos, o de que o professor deve oferecer ao aluno um ambiente variado que permita explorar e testar suas descobertas. Assim, ela sugeria que os professores diversificassem o programa de ensino, mesclando atividades didáticas e práticas para auxiliar o aluno em sua vida diária, incluindo atividades de ginástica psicológica que permitissem exercitar funçóes mentais distintas e suas reaçóes (ANTIPOFF, 1992b).

Descoeudres desenvolveu amplo trabalho na área da educação especial. Seu programa de ensino para crianças consideradas anormais mesclava, dentre outras atividades, trabalhos manuais, canto, educação dos sentidos, excursóes. Nesse programa para as classes especiais, as atividades escolares formais ocupavam um lugar secundário, pois o objetivo do ensino estava voltado para a socialização e canalização dos instintos a fim de formar hábitos de reflexão e de fixar a atenção.

Nessa perspectiva, Antipoff defendia que ensinar a ler e a escrever era uma tarefa a ser alcançada secundariamente. O trabalho manual - com o objetivo de educar para a vida, promovendo a autonomia e a formação intelectual, moral e social das crianças - e as atividades físicas e mentais ocupavam o primeiro plano, entendidos como ferramenta didática capaz de promover a formação integral dos excepcionais.

A Ortopedia Mental ofereceria o método a partir do qual os sentidos e as faculdades da inteligência, da memória, da atenção, entre outras, poderiam se desenvolver conforme as possibilidades de cada criança. Antipoff acreditava que ao perceber o êxito em atividades cotidianas básicas que incluíssem tarefas manuais e intelectuais, a criança se sentiria estimulada e passaria a manifestar interesse pelas matérias escolares. 


\section{Ortopedia Mental: um método}

Antipoff produziu um programa de exercícios de Ortopedia Mental para os professores utilizarem nas salas especiais criadas para atender crianças cujo desempenho nos testes psicológicos havia sido insatisfatório. De fato, esse método foi apropriado pelas escolas, pois na Revista do Ensino de julho-setembro de 1932, Benedita Mello, assistente técnica de ensino, descreve a experiência de uma classe D formada em sua escola. Para a elaboração de instrumentos pedagógicos a serem utilizados com os alunos dessa classe, a professora utilizou a Ortopedia Mental e os livros A educação das crianças retardadas, de Alice Descoeudres (1968), e Les idées modernes sur les enfants, de Alfred Binet (1909).

Mais do que um conjunto de exercícios, Antipoff considerou a Ortopedia Mental um método que englobava várias açóes: selecionar alunos para as classes especiais e professores com aptidóes adequadas para a aplicação do método; oferecer orientações aos professores sobre como proceder à aplicação dos exercícios; preconizar a distribuição de horários para cada atividade (ZAZZO, 2010).

Esse programa de exercícios envolvia em especial a postura do professor e o respeito às particularidades da criança para que lhe fosse despertado o interesse e, dessa forma, auxiliasse seu desenvolvimento cognitivo. A educadora empregava seus conhecimentos tanto para adaptar os exercícios de acordo com a necessidade das crianças das salas especiais, quanto para treinar os professores que os aplicariam.

$\mathrm{Na}$ Coletânea das obras escritas e no Boletim 14, desde o prefácio, Helena Antipoff explicitava seu desejo de uma constante revisão e adaptação do método: "Esta publicação não é um manual de Ortopedia Mental. É apenas uma ligeira coleção de exemplos que podem e devem variar ao infinito" (ANTIPOFF; REZENDE, 1934, p. 9). Essa variação era necessária para atender com equidade a diversidade de necessidades dos alunos que compunham cada classe. Antipoff incitava a iniciativa e a criatividade dos professores para que adequassem os exercícios à necessidade dos alunos, como se confirma a seguir: "Esperamos que as professoras das classes especiais saberão organizar outros exercícios e que nô-los comuniquem, afim de que suas 'invenções' possam ser utilizadas por outras classes além das suas” (ANTIPOFF; REZENDE, 1934, p. 9).

No mesmo Boletim, Antipoff advertia aos professores que a separação das classes era feita para privilegiar o desenvolvimento do aluno, para facilitar a preparação dos métodos, adequando-os ao nível mental do aluno. Todavia, sem o comprometimento do professor, a separação das classes, tomada como medida isolada, não traria muitos benefícios aos alunos.

Para orientar a prática do professor na utilização da Ortopedia Mental e o ensino nas classes especiais, Antipoff apropriou-se dos cinco princípios utilizados por Alice Descoeudres, nas classes especiais: oferecer maior liberdade para os alunos se desenvolverem, sem querer que eles ficassem todo seu tempo sentados nos bancos; valorizar a educação sensorial e do ensino intuitivo; concentrar os diversos ramos de ensino em torno de alguns assuntos concretos e ao alcance do interesse das crianças; utilizar o ensino individualizado a fim de suprir as necessidades individuais dos alunos, levando em conta sua situação física e mental; priorizar o caráter utilitário do ensino especial para promover a autonomia da criança, através das várias estimulaçóes. 
Nessa perspectiva, Antipoff elaborou uma proposta de Ortopedia Mental para "desenvolver ao máximo as potencialidades do excepcional, respeitando suas particularidades" (ANTIPOFF; REZENDE, 1934). Àquela época, a Ortopedia Mental já era prevista em lei em Minas Gerais: "Deter-nos-emos somente em um gênero de exercícios pouco conhecido em Minas, mas de que o vigente Regulamento da Instrução primária oficial fala e os recomenda para as classes dos retardados (art. 380)" (ANTIPOFF, 1992b, p. 165).

Quanto aos itens da Ortopedia Mental, a educadora acreditava que o exercício em si não alteraria a estrutura psicológica, mas poderia melhorar a capacidade funcional do uso das habilidades mentais, aprimorando assim o desempenho da criança.

As crianças retardadas são seres inadaptados antes de tudo. Os sentidos, a motricidade, a afetividade, o pensamento, a vontade se desencadeiam sem direção e sem ordem, de um modo caótico em umas, e inibido em outras. E é obrigaçáo do educador ajuda-las estimulando-as e organizando nelas os mecanismos psíquicos adequados aos fins (ANTIPOFF; REZENDE, 1934, p. 43).

Dessa forma, o exercício ordenado poderia organizá-las, formando hábitos. Mas para isso era necessário que a criança fizesse voluntariamente os exercícios, de maneira ativa, cabendo ao "mestre" o papel de despertar o interesse da criança pelo exercício (ANTIPOFF; REZENDE, 1934). Residia aí uma perspectiva baseada na Escola ativa de Genebra ao preconizar a estimulação associada à espontaneidade, à criatividade e à autonomia da criança.

Em todos os textos relativos à Ortopedia Mental da coletânea analisada, Helena Antipoff insistia na posição ativa tanto do aluno na tarefa, quanto do professor. Nessa percepção, com o intuito de despertar e manter o interesse do aluno era necessário que a aplicaçáo da Ortopedia Mental começasse do exercício mais simples, gradativamente passando aos mais complexos. Para a manutenção do interesse, o professor não deveria permitir que os exercícios fossem impostos ou feitos de maneira "arrastada", produzindo tédio nas crianças. A aplicação correta implicava disposição e alegria. Os exercícios deveriam ser curtos, no máximo de 15 a 20 minutos por dia, variados e flexíveis.

Antipoff criticava com veemência a rigidez na aplicação dos exercícios: “[...] as pessoas um tanto preguiçosas que em lugar de variar e inventar novos exercícios bem como novas situaçôes, só queiram empregar os mesmos, obrigando as crianças a reagir a isso apenas de um modo aprendido e mecânico" (ANTIPOFF; REZENDE, 1934, p. 47).

A intenção da educadora, na proposição da Ortopedia Mental, não era formar crianças estereotipadas, mas ajudar a organizar o que ela chamava de mecanismo psico-senso-motor, visando não a melhora de uma faculdade mental em particular, mas do conjunto delas:

[...] facilitar a disciplina, ensinar as crianças a olhar melhor para o quadro negro, a escutar melhor, reter melhor, a julgar melhor; há em jogo o amor próprio, e emulação, a perseverança, o desejo de se sair bem e todas as sensaçóes excelentes que acompanham a ação [...] (ANTIPOFF; REZENDE, 1934, p. 48). 
Junto ao exercício das faculdades mentais, o método visava desenvolver na criança um querer acentuado - interesse - que a motivasse a aprender. Partindo da concepção da psicologia ativa, para a autora o interesse era a chave da educação. Uma criança cujo interesse fosse despertado poderia ser mais autônoma na construção do conhecimento. Por isso, para a construção da autonomia da criança excepcional, Antipoff insistia para que o professor adequasse os exercícios de forma a atender as necessidades singulares dos alunos.

Tanto no Boletim 14 quanto na Coletânea das obras escritas, Antipoff menciona grupos de exercícios de Ortopedia Mental para a estimulação das mais diversas funçóes psicológicas: linguagem, imaginação, percepção, atenção, compreensão, memória, raciocínio, criatividade, imitação, observação, força, destreza, entre outras. Por estimular esse conjunto de faculdades e possibilitar o despertar do interesse nas crianças, Antipoff percebeu que os exercícios poderiam beneficiar não só as classes especiais, mas também os alunos considerados normais, de $1^{\circ}$ ano. Estes, por serem novatos na escola, poderiam ter, na Ortopedia Mental, um método que facilitasse sua integração ao ambiente escolar.

A seguir, veremos a constituição dos exercícios, a orientação de sua aplicação aos professores e as faculdades mentais a serem trabalhadas com a sua utilização.

\section{O programa geral de Ortopedia Mental}

Antipoff utilizava um programa de exercício das funçóes mentais e das modalidades intelectuais e volitivas nomeado ginástica psicológica. Nessa ginástica, é importante observar quais funções psicológicas eram utilizadas nas atividades pedagógicas, isto é, tentava-se traçar uma relação entre a atividade a ser realizada pela criança e a faculdade que tal atividade punha em jogo nessa conduta:

A psicologia experimental ainda não penetrou todos os domínios da conduta humana: o que nos parece antes de mais nada, fazer apelo à memoria, por exemplo (na experiência da repetiçáo dos algarismos) pode não depender, pela maior parte senáo da atenção: em outro exercício fazendo-nos supor sobretudo a sensibilidade tátil ou muscular, na realidade pode revelar, sobretudo, a faculdade da discriminação e do juízo (ANTIPOFF; REZENDE, 1934, p.48).

Atividades pedagógicas específicas poderiam resultar em exercícios mentais a serem explorados de diversas maneiras. Entretanto, como alertava Antipoff, não era simples dizer com exatidão qual faculdade estaria na base do exercício. Assim, repeti-lo em situaçóes diversas seria uma forma de abranger mais modalidades intelectuais.

Inicialmente publicada no Boletim 14, em 1934, e posteriormente reunida a sua obra compilada em 1992, no volume III da Coletânea das obras escritas de Helena Antipoff, a educadora detalhou a lista com 15 grupos de funções mentais e faculdades a serem exercitadas pela Ortopedia Mental: acomodação e reação aos estímulos; esforço dinâmico de rapidez e força; coordenação sensório-motora; esforço estático (inibição); imitação; compreensão de ordens verbais; observação; fixação e recognição; extensão do campo de consciência; memorização e conservação das lembranças; atenção; imaginação reprodutiva; imaginação criadora; inteligência; raciocínio. 
Helena Antipoff não traçava distinção, ao discutir a Ortopedia Mental, entre faculdades mentais e funções psicológicas. Mas poderíamos inferir que a memória, por exemplo, é a faculdade mental, enquanto memorização e conservação de lembranças são funções psicológicas que se traduzem em atos possíveis da memória. A inteligência também é uma faculdade mental. Compreensão e invenção são dois modos de a inteligência se colocar em relação com os objetos do conhecimento. Dessa maneira, um exercício de concentração fortaleceria a atividade da inteligência. Vejamos, em seguida, uma amostra de exercícios propostos pela educadora.

\section{Exercícios de Ortopedia Mental}

Os exercícios de Ortopedia Mental foram elaborados por Helena Antipoff a partir de sua própria experiência na educação de crianças excepcionais e de apropriaçóes, sobretudo dos trabalhos de Alfred Binet, Alice Descoeudres e Maria Montessori (PETERSEN, 2016).

Antipoff recomendava insistentemente, aos professores, que os exercícios de Ortopedia Mental fossem registrados em um caderno específico que tornava "possível ao mestre verificar 'a curva do progresso"” (ANTIPOFF; REZENDE, 1934, p. 53). Desse modo, observava que a ortopedia era importante tanto para treinar e educar faculdades e funçóes psicológicas, como para aferir o desenvolvimento progressivo da criança.

Os exercícios são separados em 15 grupos, como apontado no inventário discriminado ao final da seção anterior. No entanto, trabalharemos uma amostra menor com um exemplo de cada grupo em função da extensão limitada deste trabalho.

O primeiro grupo 5 corresponde à acomodação rápida e resposta motora a estímulos sensoriais ou tempo de reação simples, que reúne exercícios que trabalhariam o tempo de reação auditiva, tátil, visual e o tempo de reação discriminativa complexa, no qual a criança teria que discriminar o sinal e reagir apenas ao que fosse pedido. Essas atividades se baseiam na denominada Cadeia de Claparède:

"Cadeia de Claparède". Todas as crianças da classe fazem uma roda, dando-se as mãos (êste exercício pode ser feito, tanto no páteo, como na própria classe). O professor aí está, junto ás crianças, munido de um cronômetro. Explica-lhes que vão fazer um exercicio muito interessante, afim de verificar se elas sabem "escutar", com as mãos, as ordens que lhes vão ser transmitidas. "Escutamos as ordens com o ouvido, não é?" Vamos tentar "escutar" com as mãos, isto é, sentir a ordem que vai ser dada (ANTIPOFF; REZENDE, 1934, p. 51).

Antes da execução do exercício, os professores deveriam pedir que os alunos fechassem os olhos para que as crianças confirmassem que era possível escutar com as mãos. Só depois o exercício era feito com os olhos abertos. Borges (2014) exemplifica assim esse exercício: os alunos se posicionavam em círculo e cada criança apertava a mão do colega a sua esquerda, assim que percebesse a sua mão apertada pelo companheiro. O tempo de reação seria computado no quadro e, dessa forma, poderia treinar a atenção das crianças.

Logo, as crianças perceberiam na marcação do quadro que a cada execução do exercício o tempo diminuiria e isso serviria de estímulo para aumentar o interesse pela melhor execu-

\footnotetext{
${ }^{5}$ Os números de amostras dos grupos de exercícios de Ortopedia Mental não correspondem exatamente à ordem do inventário completo de exercícios citado, mas à ordem de apresentação no texto.
} 
ção da atividade em termos de tempo e qualidade. Aconselhava-se que a Cadeia de Claparède fosse repetida em torno de dez vezes (ANTIPOFF; REZENDE, 1934). Antipoff advertia ao professor que observasse os alunos que interrompessem o exercício e sugeria que essa criança delicadamente fosse retirada da roda e tivesse seu nome anotado, pois ter dificuldade na atividade era um indicativo do nível de atenção dessa criança. Posteriormente, o professor deveria formar, incluindo esse aluno com dificuldades, uma roda menor com menos crianças para que fosse mais fácil reter sua atenção (ANTIPOFF; REZENDE, 1934).

Esse exercício, além de estimular as funções psicológicas, proporcionaria ao professor observar as diferenças individuais, percebendo que uns reagem rapidamente, enquanto outros são demasiadamente lentos.

Os energicos, os vivos, como também os apáticos e lentos, revelam-se claramente, e do mesmo
modo as crianças nervosas, de movimentos espasmódicos, exagerados, violentos, incapazes, pelo
menos nos primeiros exercicios, de reagir tranquilamente, limitando o movimento sómente ás
máos. Nós os veremos, pelo contrário, fazer contraçóes em todo o corpo, e acompanhar a pres-
são com mil gestos e caretas. Tudo isto representa indicaçóes preciosas sôbre a reatividade das
crianças e que deverá ser educada, chamando-se, para isto, a atençáo das mesmas, afim de que
se corrijam de tais defeitos (ANTIPOFF; REZENDE, 1934, p. 52-53).

Esperava-se que, aos poucos, a criança se concentrasse melhor, conscientizando-se de seu corpo e dos movimentos, o que a levaria a dominar melhor seu corpo.

Em seguida, o grupo esforço dinâmico, que tinha como categorias rapidez e força, consistia em exercitar a execução rápida de uma tarefa e em medir e estimular a força muscular, como veremos a seguir. Uma possibilidade seria pedir que as crianças corressem no pátio da escola - aproximadamente 25 metros -, indo e voltando. Media-se e anotava-se o tempo de execução a cada 15 dias ou mês para cada aluno. A medição periódica serviria para verificar se o tempo de desempenho melhorava conforme o prolongamento do período. Se houvesse declínio da curva, cada uma das crianças pensaria que talvez não tivesse se esforçado o bastante. Já o progresso da curva significaria o progresso do grupo, fazendo com que cada aluno se sentisse bem consigo mesmo, evitando-se assim a competição. Essa corrida poderia ser ainda por saltos com um pé ou os dois pés juntos.

Em sala de aula esse exercício poderia ser praticado treinando a mão: o chamado Tapping, com duração curta de até 30 segundos. Durante um tempo as crianças fariam quantos pontos conseguissem numa folha de papel, cuidando apenas de não fazer um sobre o outro. Se for possível, a criança mesma se tornava responsável pelos pontos que conseguia.

Antipoff comentou a média de execução do tempo gasto nesse exercício: “[...] crianças de Genebra, de 7 a 12 anos, marcaram em média 60 a 70 pontos, ao passo que os mais rápidos chegaram até 100" (ANTIPOFF; REZENDE, 1934, p. 57). Assim, proporcionava uma medida de comparação para os professores brasileiros. A educadora afirmava ser importante estimular as crianças a fazerem esses exercícios sempre mais rapidamente. Segundo a autora, os alunos gostavam desse exercício, que oferecia algo de novo e um resultado rápido do seu trabalho. A criança aprenderia a realizar o melhor pelo êxito do grupo e assim alcançaria uma virtude excelente. 
O grupo coordenação sensório-motora preconizava o desenvolvimento das mãos especificamente, mas exercitando simultaneamente o controle visual. Esse grupo de exercícios era considerado de grande utilidade porque tinha a finalidade de desenvolver especificamente a destreza das mãos, habilidade necessária para a firmeza da escrita.

De acordo com a experiência da educadora em Genebra, as crianças normalmente possuíam facilidade para se movimentar livremente, mas quando se circunscrevia um movimento com limites, como o da escrita, elas podiam ser desajeitadas e lentas.

Para Antipoff, a criança cuja coordenação viso-motriz era normal, a partir dos 12 anos apresentava pouca diferença em relação à coordenação do adulto. Já nas crianças com deficiência, a coordenação costumava ser bastante comprometida. Daí a importância desses exercícios, cuja eficácia havia sido comprovada por Descoeudres com as crianças retardadas. Assim, a educadora russa advertia que o professor deveria variar e criar muitos exercícios desse grupo para utilizar sempre em sua classe (ANTIPOFF; REZENDE, 1934, p. 75).

Sabe-se que a criança menor é mais hábil em seus grandes movimentos do que nos movimentos limitados. Comecemos, pois, pelos primeiros: em uma grande sala, cujo assoalho é formado de tábuas compridas, ou no páteo, em que se podem traçar linhas de uma dezena de metros, faremos marchar as crianças sôbre essas linhas retas, bem depressa e com a maior precisão possível, isto é, só pondo os pés sôbre essas linhas. Para interessar mais as crianças dir-lhes-emos, por exemplo, que essas linhas representam uma pinguela estreitíssima sôbre um rio, ou, ainda, que são cordas suspensas no ar, como nos circos,sôbre as quais caminham acrobatas (ANTIPOFF; REZENDE, 1934, p.76).

As crianças faziam esse exercício com seriedade, imaginavam com facilidade as situações colocadas e as executavam com bastante afinco. Atividades específicas com desenhos também eram utilizadas para treino da coordenação dos olhos e das mãos. Normalmente, os primeiros desenhos eram coloridos com traços sem regularidade e ultrapassavam os contornos, levando um tempo considerável. Porém, notava-se que, com o hábito, os alunos faziam grandes progressos, sendo importante que o professor anotasse as datas das coloraçóes.

Entendemos que tanto o quarto grupo, esforço estático inibição, quanto o quinto, imitação, tinham a finalidade de suprimir os movimentos e ensinar a criança a ter controle de seu corpo, entre outros objetivos, sendo o primeiro uma preparação para o segundo. $\mathrm{O}$ exercício deste grupo tinha como característica principal manter a criança parada, imóvel. Inspirava-se no trabalho de Montessori nas "Case de Bambini".

No comêço, ao se anunciar êste exercício; seja a viva paz (sic), seja pela apresentaçáo de um cartaz no qual, em grandes letras, se tenha escrito a palavra - silêncio, seja ainda por qualquer um sinal pré determinado, agitar, por exemplo, uma bandeirinha branca ou roxa (há no roxo qualquer cousa que acalma), as crianças, necessitaráo, sem dúvida, de muito tempo, para se imobilizar, mas depois bastarão alguns segundos, sòmente o necessário para se porem nas posiçôes corporais mais cômodas e assim se manterem durante dois ou três minutos sem constrangimento (ANTIPOFF; REZENDE, 1934, p.66).

A educadora ponderou que inicialmente pareceria impossível esse exercício: primeiro aconteceriam risadas, depois pés batendo no chão, suspiros etc. Mas esses comportamentos se extinguiriam com o treino. Essa atividade poderia, inicialmente, ser sentida como repreensão, 
mas com o passar do tempo as crianças tomariam gosto pelo silêncio, produzindo efeito calmante. "Seu papel [da criança] não será, pois, desenvolver o esfôrço estático, mas de detenção física e psíquica" (ANTIPOFF; REZENDE, 1934, p.66).

O exercício era recomendado após o recreio ou atividade que acentuasse a excitabilidade. Infinitas possibilidades seriam possíveis para esses exercícios: colocar uma música tranquila e pedir que as crianças marchassem, movimentando os braços na cadência da música. Outra variação interessante é o exercício "preconizado por Binet na educação das crianças anormais. Consiste em tomar uma pose qualquer e mantê-la imóvel, durante o maior intervalo de tempo possível” (ANTIPOFF; REZENDE, 1934, p.67).

Já o exercício de imitação tinha a função de capacitar as crianças na melhora de seu domínio sobre o corpo através da imitação exata de movimentos. A orientação era dada pela ginástica sueca, e também fora utilizada por Alice Descoeudres em seu programa de ginástica psicológica. Se o professor soubesse desenhar, ele faria as posiçóes de maneira simples no quadro e os alunos reproduziriam, primeiro através de movimentos e depois através de desenhos.

O sexto grupo era compreensão de ordens verbais, que ensinava a criança a ouvir atentamente e executar uma ordem ou pedido. Esse exercício levava em conta a dificuldade da maioria das crianças, em suas primeiras semanas na escola, para executar uma ordem dada para a sala inteira. Segundo Antipoff, antes de iniciar a escola, a criança obedecia a uma ordem reportada somente a ela; então, ao ser inserida em uma turma, ela se sentiria perdida, apresentando dificuldades de entender uma ordem que não era feita diretamente a ela. Os exercícios eram feitos gradativamente: primeiro, individualmente; depois, metade da sala; finalmente, a sala toda (ANTIPOFF; REZENDE, 1934).

Sabe-se que uma criança de 2 anos já é capaz de compreender e de executar uma ordem simples, como, por exemplo, dar a bola, fechar a porta, abrir uma caixa, etc. Cumpre ter já 6 ou 7 anos para poder executar três comissóes ouvidas uma só vez. (Testes de Binet-Simon) (ANTIPOFF; REZENDE, 1934, p.73).

Para executar exercícios de compreensão de ordens verbais era muito importante que a criança entendesse bem o que fora dito e conseguisse guardar as três ordens. Essa atividade permitia trabalhar a direção do pensamento e o encadeamento da ordem (cronologia).

Outro grupo se destinava a estimular a observação e tinha como objetivo ensinar a criança a conhecer o mundo ao redor. À observação, seguia-se a atenção, um dos grupos mais importantes, segundo Antipoff, pois tornava a criança receptiva para a aprendizagem. No exercício de atenção com escolha, o professor exporia no quadro negro uma ilustração com seis desenhos de frutas ou legumes. Misturavam-se as frutas, por exemplo: seis maçãs, nove bananas, doze laranjas etc. As crianças deveriam contar separadamente cada fruta e anotar; as que não soubessem escrever, desenhariam numa folha a quantidade de cada fruta.

Além dos exercícios de atenção, também eram propostas atividades para desenvolver a capacidade de memorização de conservação de lembranças. Na elaboração e proposição dos exercícios aos escolares, Antipoff enfatizava a atuação do professor, sugerindo que ele se tornasse observador, meticuloso e comprometido com o desenvolvimento de cada aluno, bem como criativo e flexível para aplicar os exercícios e fazer tantas modificaçôes quantas fossem 
necessárias para atender as demandas de seus alunos. Suscitar o interesse da criança na execução dos exercícios era importante, já que se acreditava que a mola propulsora do desenvolvimento psíquico era a atenção. Se o que produz o desenvolvimento da criança é o interesse, que leva à atençáo, caberia ao professor oferecer o estímulo criativo principal para despertar a criança para o aprendizado. Isso era mais importante ainda no caso de crianças com deficiência que, em algum grau, estariam com os órgãos sensoriais comprometidos, necessitando de estimulação para alcançar o maior desenvolvimento de suas potencialidades.

O método de Ortopedia Mental proposto por Helena Antipoff envolvia a seleção de professores e alunos adequados para cada classe. No caso do aluno, o critério de seleção era aferido por meio dos testes de nível mental atual da criança, pois o aluno mudava de sala conforme ia se desenvolvendo. Assim, a educadora acreditava que o método da Ortopedia Mental tinha como foco o desenvolvimento dos alunos, razão principal da existência das classes especiais. Mas o projeto de educação das salas especiais só poderia funcionar se houvesse adesão dos professores na elaboração das práticas pedagógicas a serem realizadas nas turmas, levando em consideração as necessidades singulares das crianças. Por envolver as especificidades de cada classe, a Ortopedia Mental não era um programa de exercícios a ser mecanicamente executado. Pelo contrário, ele seria eficaz apenas se envolvesse o trabalho ativo do professor, único agente capaz de considerar as necessidades de seus alunos.

\section{ConsideraçóEs FinaIS}

Este estudo buscou demonstrar uma ação específica de Helena Antipoff em prol da educação especial no Brasil. Ela utilizou sua experiência sobre a psicologia da criança e seu conhecimento de autores como Édouard Claparède, Maria Montessori, Alice Descoeudres, Alfred Binet, entre outros, para compor os exercícios da Ortopedia Mental e orientar o professor a aplicá-los às turmas formadas por crianças excepcionais. Desse modo, contribuiu para a criação de instrumentos pedagógicos e psicológicos que ofereciam fundamentos científicos para a reforma de ensino em Minas Gerais.

A Ortopedia Mental, como já descrevemos neste trabalho, era constituída de exercícios para estimular faculdades mentais e funções psicológicas relacionadas à atenção, memória, criatividade, linguagem, entre outras estudadas pela psicologia da época por meio de investigaçóes como as de Alfred Binet e Belot, assim como de outros estudiosos da época. Os exercícios, se bem aplicados, proporcionariam à criança conhecer o próprio corpo e se relacionar melhor com o mundo ao interagir com os objetos e as atividades propostas.

Segundo a educadora, as crianças excepcionais possuíam as faculdades mentais desordenadas. Os exercícios ajudariam a formar hábitos que possibilitariam a exploração de objetos e o desenvolvimento a partir da interaçáo com eles e com o mundo ao redor. A formação de hábitos também ofereceria a possibilidade de essas crianças serem mais independentes, exercendo profissóes simples conforme as aptidóes desenvolvidas.

A espontaneidade era algo latente nos excepcionais, mas não seria despertada sozinha sem a ajuda de um mestre. Os exercícios seriam uma forma de chamá-los ao interesse e à atividade. Para isso, os exercícios oferecidos deveriam ser criativos, variados, conforme a necessidade dos seus alunos, beneficiando o desenvolvimento da criança e fazendo com que o aluno ficasse 
satisfeito com seus progressos. Antipoff tentava, com afinco, que professores e alunos absorvessem esse princípio. Posteriormente, ela começou a recomendar a Ortopedia Mental também para alunos novatos "normais", para ajudá-los em sua inserção escolar.

Considerando as concepçóes da época, a criação das classes especiais era um projeto que pretendia permitir que crianças consideradas excepcionais ou retardadas, em relação ao nível de aprendizagem de seus pares, tivessem acesso à educação e pudessem ser estimuladas por meio da Ortopedia Mental. Devemos lembrar que, por muito tempo, essas crianças eram destinadas a hospitais psiquiátricos e a asilos. Assim, como discute Borges (2014), pensar que a ação de separar as crianças era um ato de segregação é um olhar descontextualizado, uma vez que se deve analisar essa prática em relação às que eram realizadas na época.

Os textos analisados demonstram a experiência de Antipoff até 1934, quando estava à frente do Laboratório da Escola de Aperfeiçoamento, cuja finalidade era formar e orientar professores para que retornassem às escolas de suas cidades e ajudassem os diretores a implantar novas formas de ensino no trabalho de homogeneização das turmas, incluídas as classes especiais para atendimentos de crianças excepcionais (CAMPOS, 2012).

Campos (2003) afirma que, ao longo da década de 1930, houve um declínio dos investimentos na educação e as classes especiais começaram a receber um número excessivo de alunos, demonstrando que, provavelmente, as avaliaçóes para a classificação das crianças como excepcionais ou retardadas não estavam sendo realizadas com cuidado. Assim, as escolas públicas passaram a náo acompanhar as diretrizes do Laboratório de Psicologia no que diz respeito às possibilidades e direitos de a criança ter acesso a práticas individuadas de educação. Faltavam recursos de toda ordem. Esses fatores contribuíram para que Antipoff pensasse novas alternativas para atender os excepcionais. Uma delas foi a criação da Sociedade Pestalozzi, em 1932, por um grupo heterogêneo de pessoas - médicos, educadores e religiosos -, a fim de cuidar dos excepcionais e meninos de rua, assegurando direitos, e assessorar os professores das classes especiais que ainda existiam (BORGES, 2014).

Em 1939, o governo brasileiro negou a renovação de contrato de Antipoff devido a mudanças políticas. Logo depois, a própria Escola de Aperfeiçoamento foi fechada. Mesmo assim, Helena Antipoff resolveu se estabelecer no Brasil devido à eclosão da Segunda Guerra Mundial (1939-1945). Por volta de 1940, Antipoff e colaboradores da Sociedade Pestalozzi fundaram a Fazenda do Rosário, escola destinada a educar crianças excepcionais ao lado de outras que não apresentavam deficiências (ALMEIDA, 2013). Neste contexto, Antipoff abandonou a homogeneização das salas e fez novas experimentaçóes e inovaçôes, intensificando o uso da arte como possibilidade de desenvolvimento integral da criança (CAMPOS, 2003; ALMEIDA, 2013). Os exercícios de Ortopedia Mental, entretanto, nunca foram abandonados pela educadora russa, evidenciando sua crença na estimulação de faculdades mentais por meio de exercícios lúdicos e pedagógicos.

As iniciativas de Antipoff no campo da educação especial merecem pesquisas, pois elas trazem à tona desafios ainda atuais na educação contemporânea. Nesse sentido, estudos históricos podem oferecer contribuições para professores que, atualmente, são desafiados a criar propostas inclusivas que acolham o público da educação especial nas escolas sem descurar de suas necessidades sociais e pedagógicas. 


\section{REFERÊNCIAS}

ALMEIDA, M.O. O ensino de arte em Minas Gerais (1940-1960): diálogos e colaboraçóes entre a arte e a educação nova. 2013. 228f. Dissertação (Mestrado em Educação) - Faculdade de Educação, Universidade Federal de Minas Gerais, Belo Horizonte, 2013.

ANTIPOFF, H. Psicologia experimental. In: ANTIPOFF, H. Coletânea das obras escritas de Helena Antipoff. v. I. Belo Horizonte: Imprensa Oficial, Centro de Documentação e Pesquisa Helena Antipoff (CDPHA), 1992a.

ANTIPOFF, H. Educação do Excepcional. In: ANTIPOFF, H. Coletânea das obras escritas de Helena Antipoff. v. III. Belo Horizonte: Imprensa Oficial, Centro de Documentação e Pesquisa Helena Antipoff (CDPHA), 1992b.

ANTIPOFF, H.; REZENDE, N. Ortopedia mental nas classes especiais. Belo Horizonte: Secretaria de Educação e Saúde Pública de Minas Gerais, 1934. (Boletim, 14).

BINET, A. Les idées modernes sur les enfants. Paris: Ernest Flamarion, 1909.

BORGES, A.A.P. Entre tratar e educar os excepcionais: Helena Antipoff e a psicologia na Sociedade Pestalozzi de Minas Gerais (1932-1942). 2014. 347f. Tese (Doutorado em Educação) - Faculdade de Educação, Universidade Federal de Minas Gerais, Belo Horizonte, 2014.

CAMPOS, R.H.F. Helena Antipoff: razão e sensibilidade na Psicologia e na

Educação. Estudos Avançados, São Paulo, v. 17, n. 49, p. 209-231, 2003. Disponível em: <http://www. scielo.br/scielo.php?script=sci_arttext\&pid=S0103-40142003000300013\&lng=en\&nrm=iso $>$. Acesso em: 04 set. 2014

CAMPOS, R.H.F. Helena Antipoff: psicóloga e educadora - uma biografia intelectual. Rio de Janeiro: Fundação Miguel de Cervantes, 2012.

DESCOEUDRES, A. A educação das crianças retardadas: seus princípios, seus métodos. "Aplicação a todas as crianças". Belo Horizonte: Sociedade Pestalozzi de Minas Gerais, 1968.

GUTIERREZ, L.; BESSE, L.; PROST, A. (Ed.). Réformer l'école: l'apport de l'Éducation nouvelle (1930-1970). Notes critiques par Pierre Kahn. 2014. Disponível em: <http://histoire-education.revues. org/2885>. Acesso em: 28 jun. 2016.

LOURENÇO FILHO, M.B. Introdução ao estudo da Escola Nova. Rio de Janeiro: Ed UERJ, 2002.

MASSIMI, M.A construção da psicologia (saberes e ciências psicológicas) na cultura brasileira: uma perspectiva histórica. In: LOURENÇO, É.; ASSIS, R.M.; CAMPOS, R.H.F. (Org.). História da psicologia e contexto sociocultural: pesquisas contemporâneas, novas abordagens. Belo Horizonte: CDPHA, PucMinas, 2012. p.55-70.

NICOLAS, S. et al. Sick? Or slow? On the origins of intelligence as a psychological object. Intelligence, Edinburgh, v.41, n.5, p.699-711, 2013.

PETERSEN, L.M. A ortopedia mental: contribuiçôes de Helena Antipoff para a educação especial. 2016. 91f. Dissertação (Mestrado em Educação) - Faculdade de Educação, Universidade Federal de Minas Gerais, Belo Horizonte, 2016.

ROTA JÚNIOR, C. Recepção e circulação dos testes de inteligência na Escola de Aperfeiçoamento de Professores de Belo Horizonte (1929-1946). 2016. 156f. Tese (Doutorado em Educação) - Faculdade de Educação, Universidade Federal de Minas Gerais, Belo Horizonte, 2016. 
SIMON, T. Outros testes e aplicaçóes. Revista de Ensino, Orgam Official da Inspectoria Geral da Instrução, Belo Horizonte, v.5, n.49, p.19-27, 1930.

ZAZZO, R. Alfred Binet. Brasília, DF: MEC, 2010.

Recebido em: 07/09/2016

Reformulado em: 13/03/2017

Aprovado em: 15/03/2017 
PETERSEN, L.M. \& ASSIS, R.M. 